\title{
Organizational Health: Delineation, Constructs and Development of a Measurement Model
}

\author{
Hari A. P. Nair ${ }^{1}$, Dileep Kumar ${ }^{1} \&$ Subramaniam Sri Ramalu ${ }^{1}$ \\ ${ }^{1}$ Othman Yeop Abdullah Graduate School of Business, Universiti Utara Malaysia, Malaysia \\ Correspondence: Hari A. P. Nair, Othman Yeop Abdullah Graduate School of Business, Universiti Utara \\ Malaysia, Malaysia. Tel: 60-12-200-0433. E-mail: harinair_ap@yahoo.co.in
}

Received: April 7, 2014 Accepted: May 27, 2014 Online Published: June 24, 2014

doi:10.5539/ass.v10n14p145 URL: http://dx.doi.org/10.5539/ass.v10n14p145

\begin{abstract}
The present study examines Organizational Health $(\mathrm{OH})$ for the definition that has been inexplicably characterized and about whose significance has been a high level of variability in academician's and practitioners understanding hitherto. The purpose of this paper is to develop constructs and factors influencing $\mathrm{OH}$ within the context of the system theory in order to create a measurement model that can be used to measure business performance with Organizational changes. Data is consolidated using the Delphi technique with the opinions of experts from diverse fields within Malaysia. The study identified an $\mathrm{OH}$ measurement model consisting three multilevel constructs such as Culture \& Change Capacity, Goal Alignment and Competence Adequacy. There are 28 factors which collectively influence the degree of $\mathrm{OH}$ in an Organization. These factors are itemized to convert the model into a survey based instrument of measure. The measurement enables practitioners to identify potential deterioration of health conditions in the organization well in advance and vaccinate through appropriate and timely Organizational Development interventions.
\end{abstract}

Keywords: organizational health, goal, performance, culture, competency, change, alignment

\section{Introduction}

Organizational Health $(\mathrm{OH})$ has been a closely monitored topic with its ever growing importance and equal seriousness, both in the academic and industrial world. If we can espouse the fact that a healthy person can perform well to bring out the desired outcomes, the same can be applied to the Organizational functioning as well. It is imperative that, performance sustenance over time and tide depends directly on the Organization's ability to learn faster than the competition and its capacity to change internal structures dynamically. Every Organization wants to be healthy and successful, whatsoever small or big it is. It is not only the ability to adapt to the current environmental changes, but the anticipation about what is coming and shaping up accordingly, even before the competition realizes about it, also determines the direction of Organizational health indicator readings into the acceptable range. The objective of the present study is to develop a measurement model of $\mathrm{OH}$ by clearing the dimensional ambiguity in the literature and by identifying the appropriate constructs, underpinned by the systems theory. The constructs, thus developed are expected to provide academicians and practitioners, an integrated instrument to empirically measure $\mathrm{OH}$.

\section{Literature Review}

\subsection{Health}

'Health' has been defined by World Health Organization (WHO, 1948) as a state of complete physical, mental and social well-being and not merely the absence of pathological balance and other diseases (Jaimez \& Bretones, 2011). Janice (2000) defines Organizational health as the effectiveness of the Organization to react to changing business circumstances. It is further elaborated as the collective competency of the Organization to align, innovate and execute products and services faster, better and cheaper than the competition. Beholding a 'healthy' environment is the dream of every Organization, in order to increase productivity, growth, efficiency and reduce counterproductive behavior \& turnover of employees. To meaningfully gauge $\mathrm{OH}$, it is important to understand how it translates into meaningful performance. 


\subsection{Organizational Health}

The concept of $\mathrm{OH}$ was first discussed in literatures when Miles (1969) developed an initial configuration of OH, comprising ten core elements. Ever since, there have been many research and intellectual discussions conducted around the topic. The ten elements identified by Miles are reproduced in the Table 1 under three broad system constructs.

Table 1. Core elements of $\mathrm{OH}$ as described by Miles (1969)

\begin{tabular}{lll}
\hline Maintenance needs & Task needs & Growth and change needs \\
\hline Resource utilization & Goal focus & Autonomy \\
Cohesiveness & Communication adequacy & Adaptation \\
Morale & Optimal power & Innovativeness \\
& & Problem-solving adequacy \\
\hline
\end{tabular}

Figure 1 is a reproduction of Organizational health constructs as explained by Miles (1969) with the representation of reflective indicators of the underlying theoretical model as suggested in the present study.

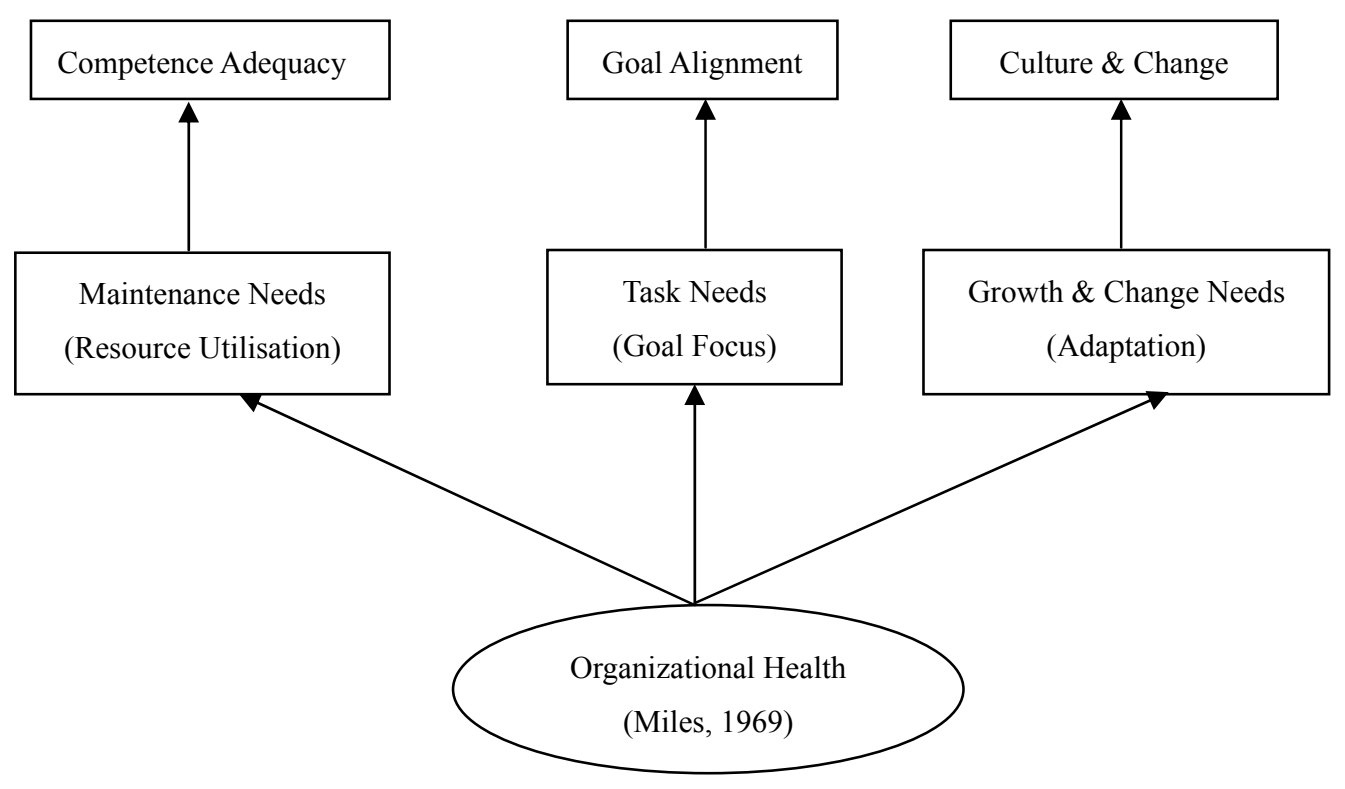

Figure 1. Reflective constructs of $\mathrm{OH}$

These constructs, on a close examination, can further be reorganized into three broad Organizational needs vide; resource readiness with appropriate competence adequacy to face the business requirements (Maintenance needs-Competence Adequacy), the ability of the Organization to ensure complete alignment of vision, values and strategy with the long term and short term goals (Task needs-Goal alignment) and the strength of culture and change capacity to adapt and innovate (Growth \& change needs- Culture \& Change capacity).

This study focuses on the interplay between these three constructs with an operational definition of $\mathrm{OH}$ expressed through a measurement model that can be used for further field research in this area. The items elaborated under each construct also provide guidance for practicing managers who are seeking to understand $\mathrm{OH}$ under changing business conditions. If the $\mathrm{OH}$ constructs can be metamorphosed into a state of three-dimensional personified existence through physical, mental and social well-being, an explanation of these distinct but integrated dimensions can be compared as constructs as given in Figure 2. 

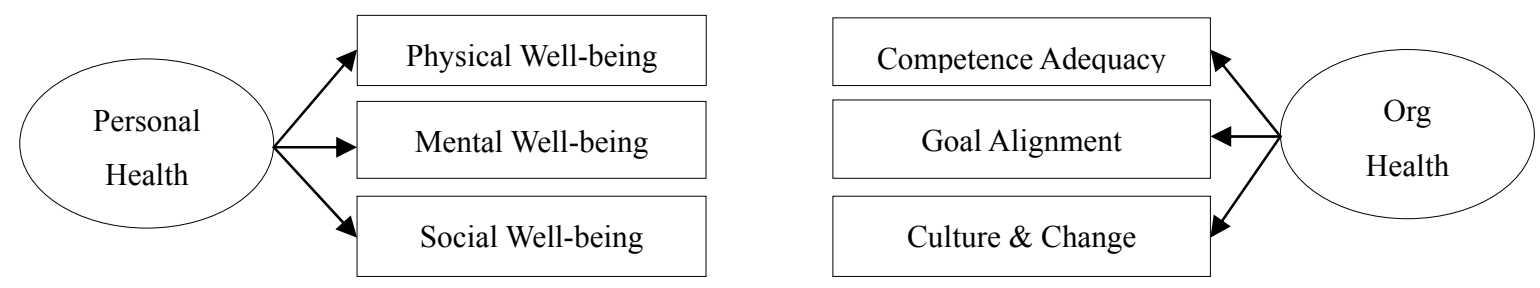

Figure 2. Personal \& organizational health

\subsection{Theoretical Underpinnings}

To explain Organizational health, it is essential to examine the aggregate health in relation to the health of various components of the Organization. Systems theory underpins this aggregate health scenario. Systems theory was conceived by a reach of scholars as a means of examining and engaging with a miscellany of topics in complex Organizational systems (Ashby, 1962; Boulding, 1956; Churchman, 1968). Systems theory elaborates into two fundamental issues: firstly, the correlation of several constituents within the Organization and with the Organization as a whole; and secondly, the kinship between the whole system and its feeder environment. There have been many concentrated studies conducted to interpret these relationships better, in the field of Organization and management, for example, in relation to learning (Argyris \& Schon, 1978; Senge, 1990). According to Brown (1997), Organizational health can be assessed by observing the verbal and visual behavioural patterns of internal communication such as employee conversations, office humour, corridor talks etc.

In a system model, each cell acts as an independent intelligent unit. These cells are held together to form the body through an enormous and a continuous stream of information. A dynamically balanced state of health is represented by the term, Homeostasis and any imbalance in the health system is represented by Inflammation which causes many if not most diseases (Chopra, 2013). If Homeostasis or well-being of a person can be derived from her habits, beliefs, attitudes and behavior, the same constructs will be applicable in case of an Organization under the realms of systems theory. While the habits and beliefs can be correlated to Culture and change capacity within a firm, the attitudes can be equated to the business readiness in terms of competitiveness and at the same time the behaviour can be explained through the business performance or the balanced goal alignment process.
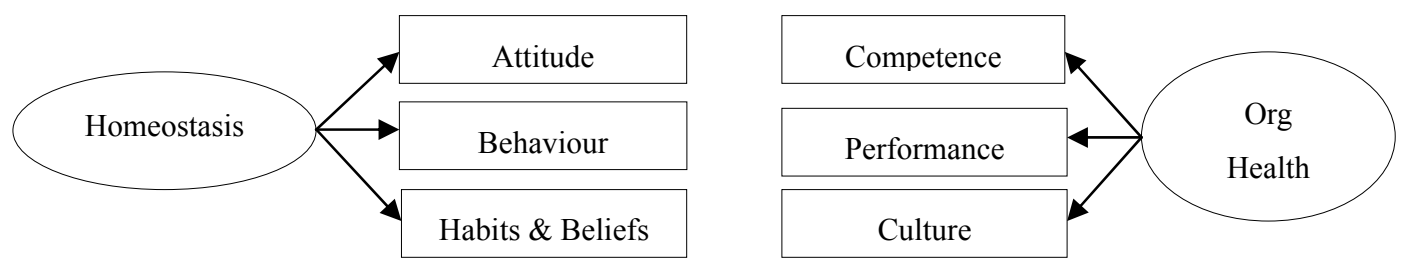

Figure 3. Comparison of $\mathrm{OH}$ with system model

\section{Organizational Health Constructs Explained}

According to McKinsey \& Company (2009), sustaining health involves concentrating towards the human side of an Organization and not so important for the management of hard numbers. This is a departure from the objective measurement driven approach suggested by the proponents of Balanced Score Card. For the purpose of this study, the researchers have adopted the Organizational Health Index, developed by McKinsey \& Company (2006) and adapted the five dimensions explained by them through culture and change capacity. These five cultural and change dimensions (Aspire, Assess, Architect, Act and Advance) explain the ebb and flow of the vision-mission journey of an Organization.

\subsection{Aspiration}

It is the beginning of any journey. Aspiring to be where the Organization wants to be and visualizing changes and challenges through the journey are harbingers of a healthy Organization. Aspiration makes change vision meaningful to employees and it defines the underlying health. 


\subsection{Assessment}

Once the aspirations are clear to all, it is essential to understand the overall readiness of the firm to bring alive those objectives. The understanding of the substantial capabilities which dictate the aspirations and current gap in such capabilities are important for Organizations to be wary of. An internal self-assessment of capabilities, mind-sets and available support ecosystem may uncover the initiatives and steps the Organizations need to take to remain healthy.

\subsection{Architect}

This is the most difficult part of the whole journey. Once the company is fully aware of its internal capabilities and where it wishes to traverse, it becomes imperative to ensure different parts of the system needs to be overhauled and refreshed to maneuver the path which is hard to navigate. At this stage the company readies itself to be an external facing, customer driven Organization. Along the journey it learns to drop the rigid and formal systems, structures and processes and trigger performance improvement initiatives.

\subsection{Act}

Acting is all about creating change concepts and proof of feasibility to create value across Organizations. McKinsey's study suggests that not too many companies move on to the step of creating a proof of feasibility. Acting also involves execution of a portfolio of initiatives to ensure intrinsic energy is unleashed on an ongoing basis. This is a phase of transformation.

\subsection{Advance}

Building upon the transformation efforts, McKinsey \& Company suggests that a host of improvement infrastructure need to be cultivated to enhance the change capacity. This will ensure sustenance of health over a period of time. Leadership development and instilling competitive spirit right through every employee is required to maintain this status of health.

Table 2. Change capacity items

\begin{tabular}{|c|c|c|c|}
\hline Source & Theory & Factor & Item \\
\hline \multirow{17}{*}{ McKinsey \& Company, 2006} & \multirow{17}{*}{ Health Index } & \multirow{3}{*}{ Aspire } & Clear business vision \\
\hline & & & Meaningful short term \& long term targets \\
\hline & & & Employees understand the determinants of health \\
\hline & & \multirow{3}{*}{ Assess } & Organization's ability to achieve its vision and targets \\
\hline & & & Uncover the root causes of Organizational health. \\
\hline & & & Company's readiness to change \\
\hline & & \multirow{5}{*}{ Architect } & Develop balanced performance improvement initiatives \\
\hline & & & Reshape the work environment to create healthy mind set \\
\hline & & & Customer driven Organization \\
\hline & & & Market focus \\
\hline & & & Openness to change \\
\hline & & \multirow{3}{*}{ Act } & Strong execution capability \\
\hline & & & Internal source of energy for change \\
\hline & & & Ability to sustain energy \\
\hline & & \multirow{3}{*}{ Advance } & Continuous improvement infrastructure \\
\hline & & & Equip leaders to lead from a core of self-mastery \\
\hline & & & Competitive spirit \\
\hline
\end{tabular}

Jaffe (1995) indicated that the performance of an Organization and its employee's health \& satisfaction are the important factors comprising Organizational health. Health is never at static state. The dynamic process of health is created and sustained through the complex integration of biological, psychological and internal Organizational processes (Macintosh, MacLean, \& Burns, 2007). Selye (1974) highlighted cohesion among team members as a fundamental prerequisite for building Organizational health. Looking at from a different angle, Gears (2011) elaborated on collaborative environment, free flow of information, and knowledge creation as quintessential components of a healthy and wealthy Organization. In the same year, another discussion on Organization health emerged when Keller and Price (2011) introduced the nine health elements encompassing leadership, direction, 
external orientation, culture and climate, capabilities, motivation, accountability, coordination and control, and innovation and learning.

\section{Balanced Score Card and Goal Alignment}

Balanced Score Card (Kaplan \& Norton, 1992) was a panacea for any goal alignment defect as the model ensured collection of all goals into four major buckets which directly impact the Organizational performance from the perspective of Customer, Stakeholders, employees and internal processes. As established through their concept of Balanced Score Card (BSC), Kaplan and Norton (1992) argued, that a performance oriented Organizational environment has always been conducive to financial growth. Through BSC, they introduced the measurement model of intangible assets of a firm which are integral part of the value creation system. Kaplan and Norton segmented such intangibles into four dimensions i.e. Customer, Financial, Learning \& Development and Internal processes.

\subsection{Customer}

From time immemorial, the importance of customer centricity remains a non-negotiable instrument in defining the products and services of a company. Customer is central to everything an Organization tries to do. With this underlying fact, the BSC identifies all the customer related initiatives and key performance indicators (KPIs) segregated under one basket. Customer Orientation, service and satisfaction are some of the most researched topics in the Organizational studies around the world.

\subsection{Financial}

Financial measures are integral part of an Organization's performance measurement matrices. Unless created for the objective of social service and non- profit, all firms look forward for revenue generation and profit maximization. All the resources, efforts and initiatives within the firm are optimized and channelized for this purpose. Continuous improvement of revenue and consistent delivery of promises to shareholders are clear indicators of the company's good health. When such indicators show declining trends, a thorough examination of the health parameters needs to be evaluated for appropriate interventions.

\subsection{Internal Process}

Processes are the vehicles for companies to carry out various initiatives in delivering services and products to market. It is essential to have an operating efficiency in each process area. The processes, thus defined should be road-worthy to take the company to the next level of growth. A great amount of flexibility is required to ensure processes are continuously re-engineered to contain the changing business scenarios.

\subsection{People}

Learning and development is an area which seldom features in any of the success scorecards of the firms. The power of learning and development was recognized by companies when the knowledge industry became predominant in the later part of the last century. People development through learning and training, thus found a strategic place in Organizational agenda.

Table 3. Goal alignment items

\begin{tabular}{|c|c|c|c|c|c|}
\hline Source & & & Theory & Factor & Item \\
\hline \multirow{12}{*}{$\begin{array}{l}\text { Kaplan } \\
(1992)\end{array}$} & \multirow{12}{*}{$\&$} & \multirow{12}{*}{ Norton } & \multirow{12}{*}{$\begin{array}{l}\text { Balanced } \\
\text { Scorecard }\end{array}$} & \multirow{3}{*}{ Customer } & The company's effort to maintain a high level of customer service \\
\hline & & & & & Customer orientation among employees \\
\hline & & & & & Ongoing measure of customer satisfaction \\
\hline & & & & \multirow{4}{*}{ Financial } & Progressive revenue achievement \\
\hline & & & & & Consistent delivery of promises to the shareholders \\
\hline & & & & & Profit maximisation \\
\hline & & & & & Internal processes suitable for growth \\
\hline & & & & \multirow[t]{3}{*}{ Process } & High operating efficiency \\
\hline & & & & & Vision, strategy and goals in the same line of sight \\
\hline & & & & & Competence for current $\&$ future business requirements \\
\hline & & & & \multirow[t]{2}{*}{ People } & Focussed learning \\
\hline & & & & & Impeccable leadership \\
\hline
\end{tabular}




\section{Competence Adequacy}

There is an integrated view of the competence displayed by various scholars through the resource based literatures, see e.g., Mahoney and Pandian (1992), Foss (1998); Foss and Knudsen (2003). With the idea of Core Competencies, Hamel and Prahalad (1994) introduced a newer approach to the Organizational health. They argued that the Core Competencies if identified and nurtured within the Organization will fetch clear and sustainable competitive advantage to the firm. With sustainable competitive advantage, a firm can attain progressive performance over a long period in comparison to the competition. The Resource-Based View (R-BV) to system hypothesizes that it is the company's 'core competencies' that give health to the establishment further bolstering economic fortune. In addition to the introduction of Resource Based Theory (RBT) by Barney (1986), Prahalad and Hamel (1990) discussed R-BV through their core competence model. Amalgamating all the R-BT and R-BV, a detailed discussion on core competencies through the theoretical characteristics of sustainable competitive advantage was initiated by Barney (1991). Competence adequacy of an Organization stems from this theory and thus the researchers have considered this as one of the constructs of $\mathrm{OH}$.

Much before the theorizing of R-BT, a resource based reasoning of firm performance from a sociological viewpoint was discussed by Price (1977). His argument on the human capital was generally referring to the headcount loss from the Organization and its consequence on the firm performance. Considering the inherent competence at varying levels involved in the human capital movement, Price's (1977) model compliments the $\mathrm{R}-\mathrm{BT}$ when evaluating $\mathrm{OH}$.

\subsection{Rarity}

While technology is driving the newer planes of competitive environment today, the growth and success of Organizations are clearly governed by the availability of knowledge and expertise i.e. The fitting competence of the business embedded in the workforce (Bartlett \& Ghoshal, 1993).

\subsection{Value}

Core competencies, if developed from within are sustainable than those picked up through imitation from the competition or adopted off the shelf and thus remain most valuable resource to the Organization (Collis, 1994).

\subsection{In-Imitability}

Intentionally inbuilt causal ambiguity makes the core competencies in-imitable, as the nature and operability of its components remain invisible and hazy making them complicated for the competition to understand copy or imitate (Teece, 1998; Teece, Pisano, \& Shuen 1997).

\subsection{Non-Substitutability}

Zander and Kogut (1995) noted that codified competencies within the firm are unique to positions, functions and domains which more importantly are aligned to the product, process and service value chain. The time and effort required to build such unique competencies make them difficult to substitute by any other related competencies by the firm itself or by the competition.

Table 4. Competence adequacy items

\begin{tabular}{|c|c|c|c|}
\hline Theory & Source & Factor & Item \\
\hline \multirow{12}{*}{ Resource Based Theory } & \multirow{12}{*}{ Barney, 1991} & \multirow{3}{*}{ Rare } & Specific industry competencies \\
\hline & & & Specific functional competencies \\
\hline & & & Specific technical competencies \\
\hline & & \multirow{4}{*}{ Valuable } & Core competencies \\
\hline & & & Future business related competencies \\
\hline & & & Competency gap management \\
\hline & & & Difficult to imitate \\
\hline & & \multirow[t]{2}{*}{ In-imitable } & Insurmountable internal capabilities \\
\hline & & & Robust competency build up \\
\hline & & \multirow{3}{*}{ Non-substitutable } & Unique competencies \\
\hline & & & Unique products \\
\hline & & & Unique marketing plans \\
\hline
\end{tabular}


A reasonable explanation to the superior performance results produced by some Organizations is the competitive advantage they possess within, in terms of the above explained competence components. Capabilities that provide superiority and sustainable competitive advantage are an Organization's core competencies. They are the renewable sources for productivity through tough market and economic conditions.

\section{Need of an Instrument}

There have been many studies and experiments conducted about Organizational health by both researchers and practitioners during the past two decades, however the definition of Organizational health has never been settled into a single agreed concept. Studies hitherto defined the $\mathrm{OH}$ as a crude combination of disparate constructs. Majority of the literature related to $\mathrm{OH}$ points to the Organizational culture, performance or employee well-being. Several studies are centered on the aggregate physical and mental health of employees. Measure of $\mathrm{OH}$ is not sufficiently explained in these studies. The instrument for such measurement is absent in the literature. The available measurement instruments for $\mathrm{OH}$ are disintegrated and dimension focused. It is thus imperative that a fitting definition to $\mathrm{OH}$ needs to be derived and an appropriate measurement instrument be developed for future use. This study attempts to address this gap by focusing on the antecedents of $\mathrm{OH}$ and developing an empirical measurement model of $\mathrm{OH}$.

\section{Research Methodology}

One of the qualitative methodologies of research followed in this study was Delphi technique which has provided exploratory insight into the major variables closely knit with the concepts under this study. The Delphi technique suggests a systematic interaction with a panel of experts who are cautiously selected based on their knowledge and experience in the specific subject (Sekaran \& Bougie, 2010). The panel of experts is given a topic for elaboration with a set of questionnaires to answer in multiple rounds. The answers to the questionnaire are consolidated by the researchers and circulated back to the panel for further elaboration, considering the opinion from other members of the panel. The panel members are given chance to iterate the previous opinion based on the newly found information and collective outlook on the topic. The rounds may continue until the researchers stop the same after having convinced that the opinions have converged into an acceptable level of consensus. In the current business research space, Delphi technique is used to forecast long range business plans. The identity of the panel members are usually not revealed among the panel to ensure an independent judgment of the topic of discussion.

\subsection{Expert Panel Identification}

For the purpose of this study, the researchers identified a group of senior professionals who are closely associated with Talent and Organizational development process in Technology and Consulting companies across Malaysia. While identifying such a versatile team, the researchers have ensured maximum possible heterogeneity in terms of gender, industry segments and job roles. The identified panel members are from varied backgrounds like, Heads of HR, Sales Managers, Consultants, Directors, Technical Architects and Academicians. The selected panel included 25 male members (78\%) and 7 female members (22\%). These experts are well experienced and considered authority in their respective area of operations. Having sufficient breadth and depth of experience in the $\mathrm{OH}$ field, these members were cautiously selected to give an opinion about $\mathrm{OH}$. Out of the 32 experts approached for this study, 27 of them gave their consent and time to conduct semi-structured interviews with them. Three rounds of interviews with panel members were conducted during the period between December 2013 and April 2014. While the majority of the interview sessions took place face to face at the member's convenience in their respective offices, few sessions were completed over the telephone. Each panel member was briefed by the researchers in detail about the objective and expected outcome from the study. All the conversations were audio recorded and analyzed separately for further details. The procedural steps at each round followed in the Delphi technique were as follows.

\subsection{Rounds}

\subsubsection{Round 1}

The first round of the Delphi the researchers set the context with the expert with few open ended questions. Open ended questionnaire helps in acquiring rudimentary facts related to the topic from the point of view of the expert which serves as an initial content sanitation of the topic (Custer, Scarcella, \& Stewart, 1999).

The open ended questions posed to the experts in the first round were:

1) How do you define Organizational Health?

2) Which are the latent constructs of Organizational Health? 
3) Which are the factors constitute the constructs of Organizational Health, contextualsing the topic to technology sector?

At this stage, the panel members' independent ideas and understanding are brainstormed; brain written and their creative thoughts around the topic are triggered by the questions (Cuhls, 2001). They are given time to think through the questions and write down/record the answers before it is collated by the researchers.

\subsubsection{Round 2}

At this stage, specific factors of agreement and disagreement under each construct are identified and sorted out to bring about a consensus on the relative importance of categories and items (Ludwig, 1994). OH related constructs and their respective factors were collected and consolidated in this round for further analysis. This is a foundational stage to derive a closer interface to implementation of $\mathrm{OH}$ as an important variable in Organizational studies by segregating distinct constructs and arriving at unique and consistent factors of measure The researchers consolidated and identified 3 distinct dimensions, 19 specific categories and 41 items under $\mathrm{OH}$ from the aggregated inputs given by the members.

\subsubsection{Round 3}

In this final round, a pre-finalized list of $\mathrm{OH}$ categories and their second order constructs with appropriate items were presented to the panelists. The panelists were requested to review the list to make any amendments to their opinions given in the second round. Thematic apperception and itemization of the categories were made in this round. There were a total of 41 items identified under each second order construct in the second round. Upon further independent evaluation of these items by the panel, there were 13 items identified as redundant or out of context by the panel. These items were removed to form a final approved list of 28 items. All the dimensions and categories identified in the second round were approved by the panel and retained in the model. Through this consensus-oriented method, a final list of second order latent constructs of $\mathrm{OH}$ and their reflective factors were identified and approved by the panel. This research study thus developed a model that defines $\mathrm{OH}$ and the related constructs and factors. The details of the analysis are incorporated in the discussion part.

Table 5. Delphi table on $\mathrm{OH}$

\begin{tabular}{|c|c|c|c|c|c|}
\hline Factor & Item & Item Code & Number of experts $(n=27)$ & $\%$ of experts & Item Status \\
\hline \multirow{3}{*}{ Aspire } & Business Vision & $\mathrm{OHCC1}$ & 23 & $85 \%$ & \\
\hline & Short \& Long term Targets & $\mathrm{OHCC} 2$ & 21 & $78 \%$ & \\
\hline & Determinants of health & OHCC3 & 18 & $67 \%$ & \\
\hline \multirow{3}{*}{ Assess } & Organizational ability & OHCC4 & 21 & $78 \%$ & \\
\hline & Identify causes of issues & OHCC5 & 20 & $74 \%$ & \\
\hline & Readiness for change & OHCC6 & 26 & $96 \%$ & \\
\hline \multirow{5}{*}{ Architect } & Performance improvement & OHCC7 & 23 & $85 \%$ & \\
\hline & Work environment & OHCC8 & 21 & $78 \%$ & \\
\hline & Customer drive & OHCC9 & 8 & $30 \%$ & Dropped \\
\hline & Market focus & OHCC10 & 25 & $93 \%$ & \\
\hline & Openness & OHCC11 & 27 & $100 \%$ & \\
\hline \multirow{3}{*}{ Act } & Execution capability & $\mathrm{OHCC} 12$ & 21 & $78 \%$ & \\
\hline & Internal source of energy & $\mathrm{OHCC} 13$ & 23 & $85 \%$ & \\
\hline & Energy sustenance & $\mathrm{OHCC} 14$ & 12 & $44 \%$ & Dropped \\
\hline \multirow{3}{*}{ Advance } & Continuous improvement & $\mathrm{OHCC} 15$ & 23 & $85 \%$ & \\
\hline & Leadership & $\mathrm{OHCC} 16$ & 26 & $96 \%$ & \\
\hline & Competitive spirit & $\mathrm{OHCC} 17$ & 11 & $41 \%$ & Dropped \\
\hline \multirow{3}{*}{ Customer } & Measure of customer satisfaction & OHGA1 & 25 & $93 \%$ & \\
\hline & Customer service & OHGA2 & 25 & $93 \%$ & \\
\hline & Customer orientation & OHGA3 & 23 & $85 \%$ & \\
\hline \multirow{3}{*}{ Financial } & Revenue achievement & OHGA4 & 27 & $100 \%$ & \\
\hline & Delivery of promises & OHGA5 & 25 & $93 \%$ & \\
\hline & Maximise profit & OHGA6 & 13 & $48 \%$ & Dropped \\
\hline Business Process & Strong processes & OHGA7 & 26 & $96 \%$ & \\
\hline
\end{tabular}




\begin{tabular}{|c|c|c|c|c|c|}
\hline Factor & Item & Item Code & Number of experts $(n=27)$ & $\%$ of experts & Item Status \\
\hline & Operating efficiency & OHGA8 & 24 & $89 \%$ & \\
\hline & Line of sight on vision & OHGA9 & 12 & $44 \%$ & Dropped \\
\hline & Career growth & OHGA10 & 23 & $85 \%$ & \\
\hline \multirow[t]{3}{*}{ People } & learning & OHGA11 & 21 & $78 \%$ & \\
\hline & Leadership & OHGA12 & 5 & $19 \%$ & Dropped \\
\hline & Industry competencies & OHCA1 & 25 & $93 \%$ & \\
\hline \multirow[t]{3}{*}{ Rare } & Functional competencies & OHCA2 & 10 & $37 \%$ & Dropped \\
\hline & Technical competencies & OHCA3 & 12 & $44 \%$ & Dropped \\
\hline & Core competencies & OHCA4 & 22 & $81 \%$ & \\
\hline \multirow[t]{3}{*}{ Valuable } & Future business focus & OHCA5 & 19 & $70 \%$ & \\
\hline & Gap management & OHCA6 & 9 & $33 \%$ & Dropped \\
\hline & Difficult to imitate & OHCA7 & 26 & $96 \%$ & \\
\hline \multirow[t]{3}{*}{ In-imitable } & Internal capabilities & OHCA8 & 11 & $41 \%$ & Dropped \\
\hline & Competency build up & OHCA9 & 7 & $26 \%$ & Dropped \\
\hline & Unique competencies & OHCA10 & 25 & $93 \%$ & \\
\hline \multirow[t]{2}{*}{ Non-substitutable } & Unique products & OHCA11 & 12 & $44 \%$ & Dropped \\
\hline & Unique marketing plans & OHCA12 & 10 & $37 \%$ & Dropped \\
\hline
\end{tabular}

The first construct considered for the study is the Culture \& Change Capacity of Organizations which was adapted from McKinsey \& Company's OH Index report. The categories (aspire, assess, architect, act \& advance) mentioned in the report were maintained for this study as the instrument using these categories was validated by McKinsey \& Company in their previous Organizational studies. The members of the panel acknowledged these categories as relevant for the $\mathrm{OH}$ measure. Under this category, further 17 items were suggested and developed by the panel members independently in the second round. In the third round, when the items were consolidated and circulated back, three of the items were identified as redundant under this category as less than $50 \%$ of the members chose them as relevant. These factors are Customer Driven Organization (30\%), Ability to sustain energy (44\%) and Competitive Spirit (41\%). These items were dropped from the final list during the 3rd round. A final total of 14 items were retained and approved by the members under the category, Culture \& Change Capacity. These items are Clear Business Vision (85\%), Meaningful Short \& Long term targets (78\%), Employee's understanding about determinants of health (67\%), Organization's ability to achieve its vision and targets (78\%), Uncovering the root causes of Organizational health (74\%), Organization's readiness to change (96\%), Developing balanced performance-improvement initiatives (85\%), Reshaping the work environment to create healthy mind-sets (78\%), Market focus (93\%), Openness to change (100\%), Strong execution capability (78\%), Internal source of energy for change (85\%), Continuous improvement infrastructure (85\%) and Equipping leaders to lead from a core of self-mastery (96\%). It is interesting to note that items such as Leadership, Readiness \& Openness to Change and Market focus scored incredibly high by the panel members.

The second construct, Goal Alignment was adapted from the concept of Balanced Scorecard (BSC) developed by Kaplan \& Norton (1992). The four dimensions of the BSC as suggested by the architects of this concept were well acknowledged by the Delphi panel members. As the predominant goal items of an Organization can be categorized into the four perspectives vide, Customer, Financial, Internal process and Learning \& Development, there was no much disagreement among the panel members on the items. However, the panel unanimously suggested to rename the dimension 'Learning \& Development (L\&D)' to 'People' as the consequences of L\&D impacts people of the Organization who ultimately are the vehicles of $\mathrm{OH}$ build up. During the second round, a total of 12 items under this construct were collated from the members. While re-examining these items in the 3rd round, three of the items were ranked low by the members. These items are Profit Maximization (48\%), Vision, strategy and goals in the same line of sight (44\%) and impeccable leadership (19\%). The item leadership was scored lower by the members as the same was featuring as a high scoring item in the Culture \& Change construct as well. The items which were cleared by the panel are On-going measure of customer satisfaction (93\%), Organization's effort to maintain high level of customer service (93\%), Employees are highly customer oriented (85\%), Progressive revenue achievement (100\%), Consistent delivery of promises to the shareholders (93\%), internal processes suitable for growth (96\%), High operating efficiency $(89 \%)$, Career growth opportunities $(85 \%)$ and Focused learning (78\%). It is worth noting the point that Revenue growth was unanimously identified as the most important factor of this construct. 
The third and last construct which correlated to $\mathrm{OH}$ as evaluated by the panelists was Competence Adequacy. This construct was featured in the Delphi discussions with the theoretical support of Resources Based Theory expanded by Barney (1991). The construct also was fundamentally supported by the Core Competencies explained by Hamel \& Prahalad (1994). The four dimensions of core competencies picked for discussion and acknowledged by the panel were Rare, Valuable, In-imitable \& Non-substitutable. Under these dimensions, the panel came up with twelve items to be evaluated. During the third round of Delphi, only five items out of the initial twelve were retained by the members. The other seven items were found to be redundant and repeated after accepting the similar items in other constructs of $\mathrm{OH}$ as discussed earlier. The items retained after the 3rd round are Specific industry competencies (93\%), Core competencies (81\%), Future business related competencies (70\%), Difficult to imitate $(96 \%)$ and unique competencies $(93 \%)$. Since there are only five items remaining in this construct, the same has been modified to a single order construct by ignoring the dimensions.

\section{Discussion}

This research study focused on developing an integrated measurement model for $\mathrm{OH}$ with clearly defined constructs, which were hitherto observed and measured as independent items as explained in the literature from previous studies. Opinions of industry and academic experts who are closely associated with Organizational studies were collected to construct the $\mathrm{OH}$ model. From the study, it has been imperative that there are three major constructs such as Culture \& Change Capacity, Goal Alignment and Competence Adequacy which constitute the antecedents of $\mathrm{OH}$. Under these constructs, as observed and identified by the panel members through a Delphi exercise over three months, there exist 28 measurable factors, which form the bricks and stones of the $\mathrm{OH}$ model. The constructs identified by the expert panel in this study reasonably confirm to the $\mathrm{OH}$ constructs as explained by Miles (1969). The model developed in this study is also greatly supported by the Organizational System Theory conceived and elaborated by a range of scholars (Ashby, 1962; Boulding, 1956; Churchman, 1968) and the Homeostasis model advocated by Chopra (2013) as well.

When a firm delivers all its committed targets to the stakeholders, it is said to have performed well. There are several key indicators to rightfully measure performance through Net Profit after Tax, Return on Capital Employed (ROCE), dividend to shareholders, market capitalization etc. To sustain health over a period of time in the business space, an Organization needs to continually realign with market realities, quickly renew its internal energy sources and execute with precision, more importantly faster than its closest competition. The essential elements of health are different according to the business context the Organization operates in. However, the fundamental Organizational capabilities like internal competence strength, collective execution capabilities, change capacity, culture, speed to market and external orientation skills etc. augment the strength of health parameters substantially.

The first construct Culture \& Change Capacity adapted in this study explain a gradual and logical progression of an Organizations internal capability build up through the five dimensions. "The first step in such capacity building is to have a collective Organizational aspiration to reach a pre-defined goal", opines the Regional Talent Head of a Global consulting firm. She feels that it is important to break up these goals into short and long term targets and the same be communicated across the Organization from time to time. "It is essential for employees to understand the constituents of health and to be wary about any deterioration noticed during the course of business", expresses the South Asia Director of a Software Services company. Internal assessment of capabilities as one of pillars of culture \& change was supported with a strong voice by the panel members. As put forth by a Program Manager of a Software product firm, readiness to change is quintessential for the companies today as the climatic changes in the business are so rampant with the impending changes in global economic situations. When discussed about the $\mathrm{OH}$ issues, a Group Head of Commercial from an Asian Telecommunication company mentioned that, if a company is able to uncover the root cause of growth impediments, it can raise itself to a healthy status with concentrated efforts in the considerably shorter timeframe than otherwise.

The third dimension of Culture \& Change was one of the topics discussed at length by the panelists over the sessions. 'Keeping all the doors open to the market' is a brief definition given for Openness to Change by a Senior Manager from a Consulting firm. Architecting the finer structure of the Organization demands mindful intervention into the firms' performance by establishing solid improvement infrastructure. Majority of the panel members reiterated the importance of reshaping work environment, encouraging creative mindsets, market focus etc. in designing the change towards sustainable health.

Revenue achievement was one of the highest scored factors under the Goal Alignment construct. Balanced Score Card (BSC) remained a favorite topic of discussion among the panel members throughout the Delphi exercise. In the first round the concept of BSC was concurrently taken up by many several members and supported by most 
of the rest. Operating efficiency, robust processes, learning focus, alignment etc. were a few of the key words picked up and retained in the factor sheet by the researchers during the sessions.

When three panel members raised the topic of Competitive advantage in the first round, there were varied and distributed reaction from the rest of the members in the second round. While competency development as a whole was agreed upon as an important requirement for $\mathrm{OH}$, competency building at functional and technical level was not considered to be a major change factor in $\mathrm{OH}$. There was a convergence of opinion when discussed about the rarity, value, in-imitability and non-substitutability of firm specific competencies.

Through the journeys of profitable Organizations, it has been empirically proven that the intensity of impact the Culture \& Change, Goal Alignment and Competence can bring in intrinsic health to the Organizations. Culture flows like life blood through the organization to instigate right thoughts, words and actions among employees. When health starts to decline, companies become vulnerable not only to drop in productivity, but also to poorer customer service and greater rates of absenteeism and turnover.

\section{Implications}

In this study, the researchers have attempted to clear the ambiguity around the $\mathrm{OH}$ concept by integrating the hitherto disparate constructs of Culture \& Change Capacity, Goal Alignment and Competence Adequacy. The researchers, through a three month long, rigorous interactive sessions, contacted experts from the Industry and Academic fields to collect, collate and aggregate opinions to deduct reasonable inferences to develop a an integrated $\mathrm{OH}$ model. The model thus developed can be converted into an instrument to measure $\mathrm{OH}$ from a holistic perspective covering all the dimensions of health. The model harmoniously interlocks the undisputed concepts of culture \& Change Index, Balanced Scorecard and Competitive Advantage into a singular plane. The researchers believe that this model can serve as a ready reckoner for those practitioners who are concerned about changing business situations and the resultant impact of it on their Organization's health. The model will have a positive influence on Technology Organizations where the waves of change sweep in at unprecedented speed. Barring the McKinsey Organizational Index survey, which measures the effect of change \& culture on $\mathrm{OH}$, no other established instrument is available today for Organizations to feel the pulse.

\section{Conclusion}

This qualitative study throws light to the $\mathrm{OH}$ constructs and further establishes the factors influencing $\mathrm{OH}$, leading to the development of an integrated $\mathrm{OH}$ model. Despite the fact that a few firms have understood the significance of measuring $\mathrm{OH}$, they mostly do not know precisely what to measure, because of an absence of understanding of what constitutes a set of $\mathrm{OH}$ dimensions. By proposing, creating, and validating a multi-dimensional, operational measure of the $\mathrm{OH}$, and by showing its viability in enhancing Organizational performance, the present study gives practitioners a handy instrument for assessing the extensiveness of their current $\mathrm{OH}$ initiatives. The experts while interacting through the Delphi technique expressed a uniform opinion regarding the $\mathrm{OH}$ constructs and its factors. These experts were chosen based on their vast and varied experience in Organizational development activities in Malaysia and outside. The experts possess deep and broad knowledge of the topic given for discussion and review and thus we are confident that the constructs in the $\mathrm{OH}$ model stands firm for its reliability and validity. This, we believe is a significant contribution to the body of knowledge. The model can further be expanded into a customizable, evidence-based instrument to measure $\mathrm{OH}$, which we are sanguine that will be a considerable contribution to the industry.

\section{References}

Argyris, C., \& Schon, D. A. (1978). Organizational Learning: A Theory of Action Perspective. Reading, MA: Addison Wesley.

Ashby, W. R. (1962). Principles of the self-organizing system. In H. von Foerster, \& G. W. Zopf (Eds.), Principles of Self-Organization: Transactions of the University of Illinois Symposium. London: Pergamon.

Barney, J. B. (1986). Strategic factor markets: Expectations, luck, and business strategy. Management Science, 32(10), 1231-1241. http://dx.doi.org/10.1287/mnsc.32.10.1231

Bartlett, Christopher, A., \& Ghoshal, S. (1993). Beyond the M-form: Toward a Managerial Theory of the Firm. Strategic Management Journal, 14(2), 23-46. http://dx.doi.org/10.1002/smj.4250141005

Boulding, K. E. (1956). General systems theory: The skeleton of science. Management Science, 2, 197-208. http://dx.doi.org/10.1287/mnsc.2.3.197

Brown, E. H. (1997). Improving Organizational health by addressing Organizational trauma. Journal of Organizational Change Management, 10(2), 175-178. http://dx.doi.org/10.1108/09534819710160835 
Chopra, D. (2013). Your Brain Is the Universe. Healthy Living. Huffpost. Retrieved February 4, 2014, from http://www.huffingtonpost.com/tag/homeostasis

Churchman, C. W. (1968). The Systems Approach. New York: Delta.

Collis, D. J. (1994). Research note: How valuable are Organizational capabilities? Strategic Management Journal, 15, 143-152. http://dx.doi.org/10.1002/smj.4250150910

Cuhls, K. (2000). Opening up Foresight Processes. In Économies et Sociétés, Série Dynamique technologique et Organization, (5), 21-40.

Custer, R. L., Scarcella, J. A., \& Stewart, B. R. (1999). The modified Delphi technique: A rotational modification. Journal of Vocational and Technical Education, 15(2), 1-10.

Foss, N. J. (1998). Equilibrium vs evolution in the resource based perspective; the conflicting legacies of demsetz and penrose. In N. J. Foss, \& P. R. Robertson (Eds.), Resources, Technology and Strategy: Explorations in the Resource-Based Perspective. Routledge, London.

Foss, N. J., \& Knudsen, C. (2003). The Resource-Based Tangle: Towards a Sustainable Explanation of Competitive Advantage. Thorbjorn Managerial and Decision Economics, 6, 4-29.

Gears, D. A. (2011). Wiki behavior in the workplace: Emotional aspects of content development. Unpublished dissertation, Graduate School of Computer and Information Sciences, Nova Southeastern University, Fort Lauderdale, FL.

Hamel, G., \& Prahalad, C. K. (1994). Competing for the Future. Harvard Business School Press. Boston, MA.

Jaffe, D. (1995). The healthy company: Research paradigms for personal and Organizational health. In S. Sauter, \& L. Murphy (Eds.), Organizational Risk Factors for Job Stress (pp. 13-40). Washington, DC: American Psychological Association. http://dx.doi.org/10.1037/10173-001

Jáimez, M. J., \& Bretones, F. D. (2011). Towards A Healthy Organization Model: The Relevance of Empowerment. ISGUC. Journal of Industrial Relations and Human Resources, 13(3), 7-26. http://dx.doi. org/10.4026/1303-2860.2011.0180.x

Janice, T. S. (2000). Managing Organizational health and performance in junior colleges. International Journal of Educational Management, 14(2), 62-73. http://dx.doi.org/10.1108/09513540010315896

Joseph, T. M., \& Rajendran, J. P. (1992). The Resource-Based view within the conversation of strategic management. Strategic Management Journal, 13, 363-380. http://dx.doi.org/10.1002/smj.4250130505

Kaplan, R. S., \& Norton, D. P. (1992). The balanced scorecard-measures that drive performance. Harvard Business Review, 70(1), 71-79.

Keller, S., \& Price, C. (2011). Organizational health: The ultimate competitive advantage. McKinsey Quarterly, (6), 1-13.

Ludwig, B. (1997). Predicting the future: Have you considered using the Delphi methodology? Journal of Extension, 35(5), 1-4. Retrieved November 6, 2013, from http://www.joe.org/joe/1997october/tt2.html

MacIntosh, R., MacLean, D., \& Burns, H. (2007). Health in Organization: Towards a process-based view. Journal of Management Studies, 44, 206-221. http://dx.doi.org/10.1111/j.1467-6486.2007.00685.x

MacLean, D., \& MacIntosh, R. (2002). One process, two audiences: On the challenges of management research. European Management Journal, 20, 383-392. http://dx.doi.org/10.1016/S0263-2373(02)00058-0

McKinsey \& Company. (2009). Changing the fortunes of America's workforce-a human capital challenge. Retrieved October 22, 2013, from http://www.mckinseyonsociety.com/downloads/reports/EconomicDevelopment/Changing_fortunes_of_Americas_workforce.pdf

Miles, M. B. (1969). Planned change and Organizational health: Figure and ground. In E. A. Carver, \& T. J. Sergiovanni (Eds.), Organizations and Human Behaviour (pp. 375-391). McGraw-Hill, New York, NY.

Prahalad, C. K., \& Hamel, G. (1990). The core competence of the corporation. Harvard Business Review, 68(3), 79-91.

Price, J. L. (1977). The Study of Turnover. Iowa State University Press: Ames, IA.

Sekaran, U., \& Bougie, R. (2010). Research methods for business: A skill-building approach (5th ed.). Wiley, Chichester.

Selye, H. (1974). Stress without Distress (3rd ed.). Harper \& Row, New York, NY. 
Senge, P. (1990). The fifth discipline. New York: Doubleday Currency.

Teece, D. J. (1998). Capturing value from knowledge assets: The new economy, markets for know-how and intangible assets. California Management Review, 40(3), 55-79. http://dx.doi.org/10.2307/41165943

Teece, D. J., Pisano, G., \& Shuen, A. (1997). Dynamic capabilities and strategic management. Strategic Management Journal, 18(7), 509-533. http://dx.doi.org/10.1002/(SICI)1097-0266(199708)18:7<509::AIDSMJ882>3.0.CO;2-Z

World Health Organization. (1948). WHO Definition of Health. Retrieved December 7, 2013, from http://www.who.intlabout

Zander, U., \& Kogut, B. (1995). Knowledge and the speed of the transfer and imitation of Organizational capabilities: An empirical test. Organization Science, 6, 76-92. http://dx.doi.org/10.1287/orsc.6.1.76

\section{Copyrights}

Copyright for this article is retained by the author(s), with first publication rights granted to the journal.

This is an open-access article distributed under the terms and conditions of the Creative Commons Attribution license (http://creativecommons.org/licenses/by/3.0/). 